\title{
Erratum: A platform pathway for production of 3-hydroxyacids provides a biosynthetic route to 3-hydroxy- $\boldsymbol{\gamma}$-butyrolactone
}

Collin H. Martin, Himanshu Dhamankar, Hsien-Chung Tseng, Micah J. Sheppard, Christopher R. Reisch \& Kristala L.J. Prather

Nature Communications 4:1414 doi: 10.1038/ncomms2418 (2013); Published 29 Jan 2013; Updated 29 Jul 2013

In Fig. 3 of this Article, the $y$ axis label was inadvertently changed from $\mathrm{mM}$ to $\mathrm{nM}$ during the production process. The correct version of the figure appears below.
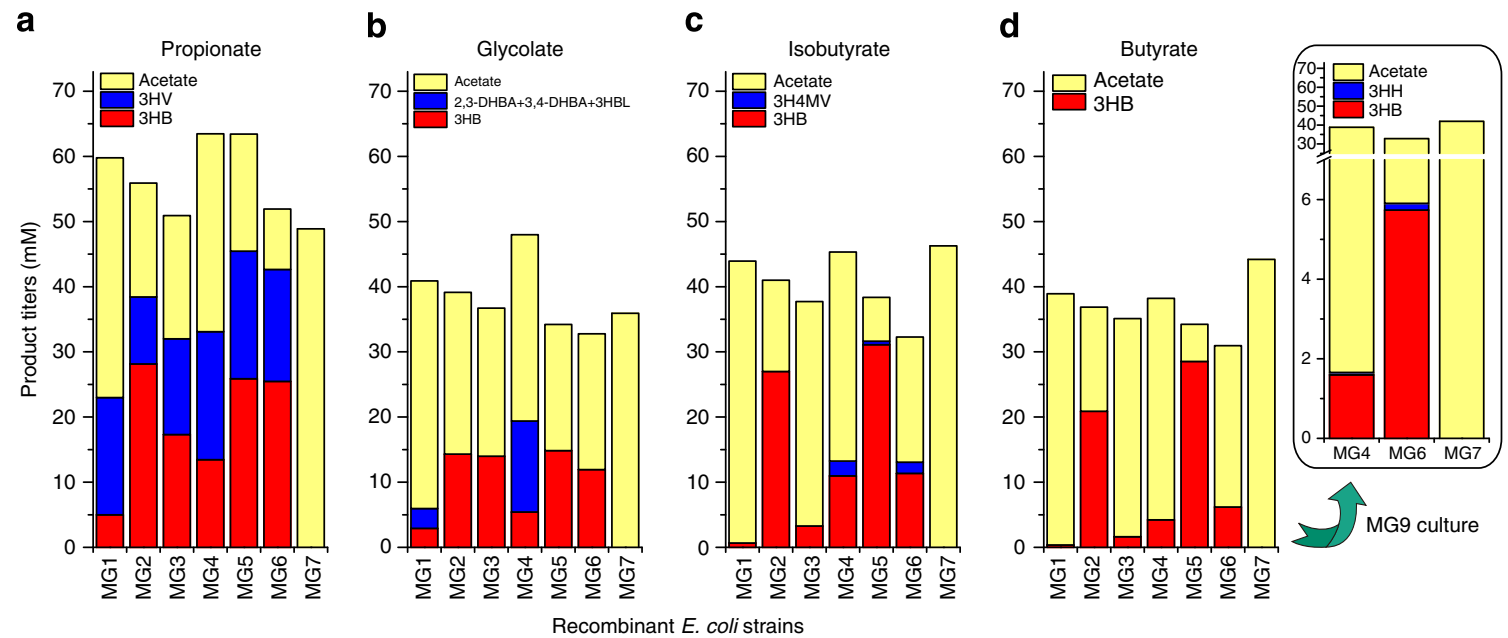